\title{
Hepatitis A outbreak linked to imported frozen strawberries by sequencing, Sweden and Austria, June to September 2018
}

Theresa Enkirch ${ }^{1,2}$, Ronnie Eriksson ${ }^{3}$, Sofia Persson ${ }^{3}$, Daniela Schmid ${ }^{4}$, Stephan W. Aberle ${ }^{5}$, Emma Löf ${ }^{1,6}$, Bengt Wittesjö7, Birgitta Holmgren ${ }^{8}$, Charlotte Johnzon 9 , Eva X. Gustafsson ${ }^{8}$, Lena M. Svensson ${ }^{10}$, Lisa Labbé Sandelin ${ }^{11}$, Lukas Richter ${ }^{4}$, Mats Lindblad ${ }^{3}$, Mia Brytting ${ }^{1}$, Sabine Maritschnik ${ }^{4}$, Tatjana Tallo ${ }^{1}$, Therese Malm ${ }^{12}$, Lena Sundqvist ${ }^{1}$, Josefine Lundberg Ederth ${ }^{1}$

1. Public Health Agency of Sweden, Solna, Sweden

2. European Programme for Public Health Microbiology Training (EUPHEM), European Centre for Disease Prevention and Control (ECDC), Stockholm, Sweden

3. National Food Agency, Uppsala, Sweden

4. Austrian Agency for Health and Food Safety, Vienna, Austria

5. Center for Virology, Medical University of Vienna, Vienna, Austria

6. European Programme for Intervention Epidemiology Training (EPIET), European Centre for Disease Prevention and Control, (ECDC), Stockholm, Sweden

7. Department of Communicable Disease Control and Prevention, Blekinge County, Sweden

8. Department of Communicable Disease Control and Prevention, Skåne County, Sweden

9. The Environment and Health Administration of Stockholm Municipality, Stockholm, Sweden

10. Department of Communicable Disease Control and Prevention, Östergötland County, Sweden

11. Department of Communicable Disease Control and Prevention, Kalmar County, Sweden

12. Department of Communicable Disease Control and Prevention, Gävleborg County, Sweden

Correspondence: Theresa Enkirch (Theresa.Enkirch@folkhalsomyndigheten.se)

Citation style for this article:

Enkirch Theresa, Eriksson Ronnie, Persson Sofia, Schmid Daniela, Aberle Stephan W., Löf Emma, Wittesjö Bengt, Holmgren Birgitta, Johnzon Charlotte, Gustafsson Eva X., Svensson Lena M., Sandelin Lisa Labbé, Richter Lukas, Lindblad Mats, Brytting Mia, Maritschnik Sabine, Tallo Tatjana, Malm Therese, Sundqvist Lena, Ederth Josefine Lundberg. Hepatitis A outbreak linked to imported frozen strawberries by sequencing, Sweden and Austria, June to September 2018 . Euro Surveill. 2018;23(41): pii=1800528. https://doi.org/10.2807/1560-7917.ES.2018.23.41.1800528

Between June-September 2018, 20 hepatitis A cases were notified in six counties in Sweden. Combined epidemiological and microbiological investigations identified imported frozen strawberries produced in Poland as the source of the outbreak. Sequence analysis confirmed the outbreak strain IB in the strawberries with $100 \%$ identity and the respective batch was withdrawn. Sharing the sequence information internationally led to the identification of 14 additional cases in Austria, linked to strawberries from the same producer.

Hepatitis A virus is an important cause of food-borne diseases and has been associated with several European outbreaks linked to berries [1-4]. Here, we describe an ongoing outbreak of hepatitis A virus (HAV) in Sweden and Austria and the confirmation of frozen strawberries imported from Poland as the source of infection. The aims are to highlight the importance of sequencing in outbreak investigations and, due to the long shelf-life of the food vehicle, to increase awareness and warnings towards HAV infections related to frozen strawberries in Europe.

\section{Outbreak identification}

On 14 June 2018, the Public Health Agency of Sweden (PHAS) received a notification from the Regional Office of Communicable Disease Control and Prevention of a suspected local outbreak of HAV in County A with five cases. An epidemiological investigation was initiated by county $A$ together with PHAS and the National Food Agency (NFA).

Between 11 June and 27 July 2018, 20 confirmed and probable cases were reported from six counties (Figure 1). HAV genotyping of 17 of the 20 cases confirmed an identical genotype IB strain (the outbreak strain).

\section{Case definition}

A confirmed case was defined as a person with laboratory-confirmed hepatitis $A$ and dates of symptoms onset after 1 May 2018 (Sweden) or 1 June 2018 (Austria) and with a sequence identical to the HAV subgenotype IB outbreak strain $\left(\mathrm{MH}_{730560}\right.$, submitted to GenBank), based on an overlapping fragment of the $\mathrm{VP}_{1} / \mathrm{P}_{2} \mathrm{~A}$ region. Probable cases were those diagnosed with hepatitis $A$ with an epidemiological link to the strawberries of the identified producer but who were not sequence-confirmed.

\section{Epidemiology}

As at og October 2018, the outbreak in Sweden comprised 20 cases, of whom 17 were confirmed cases and three were probable. Dates of symptom onset ranged 


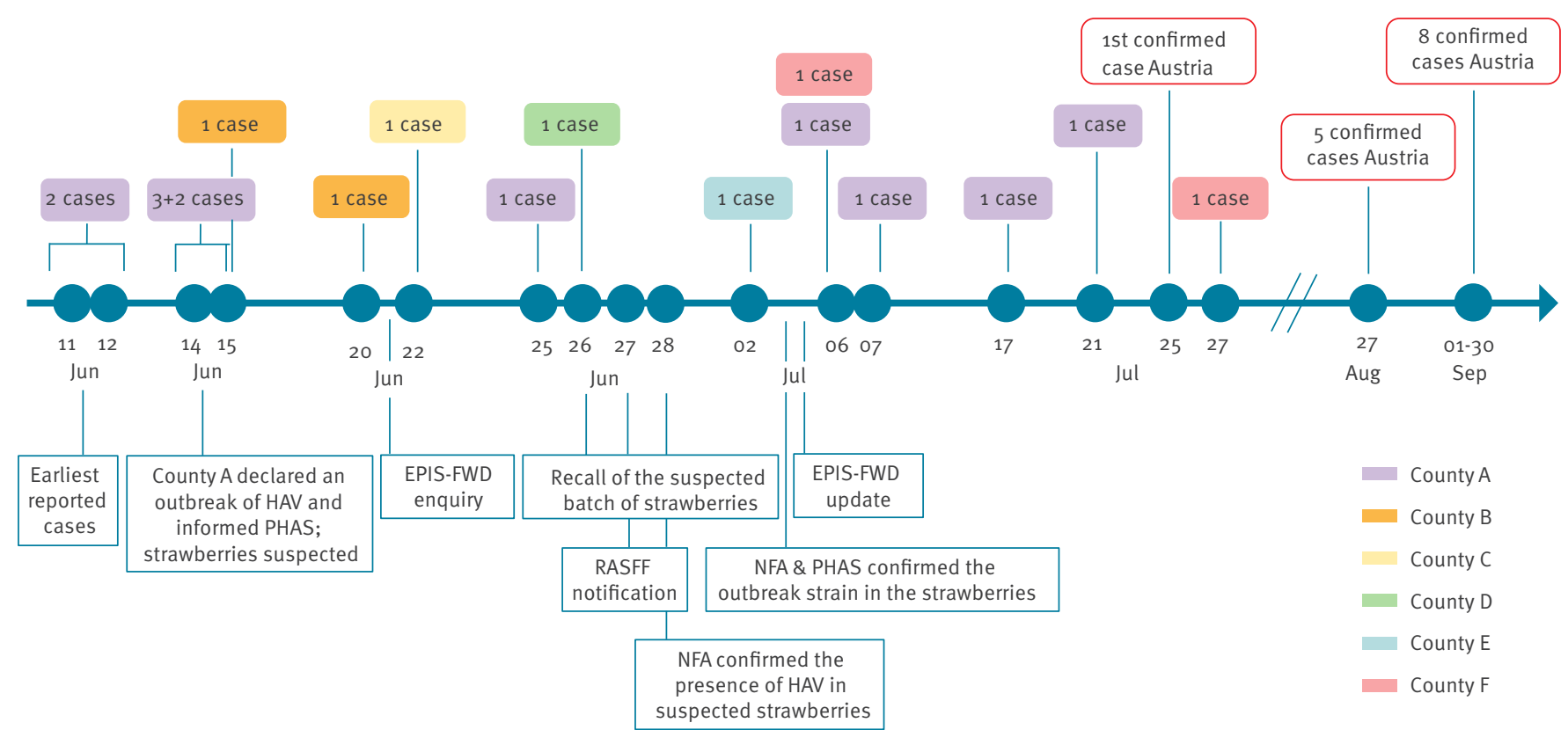

EPIS-FWD: Epidemic Intelligence Information System for Food- and Waterborne Diseases and Zoonoses; HAV: hepatitis A virus; NFA: National Food Agency (Sweden); PHAS: Public Health Agency of Sweden; RASFF: Rapid Alert System for Food and Feed.

${ }^{a}$ Confirmed cases: Sweden 17, Austria 14; Probable cases: Sweden 2, Austria currently unknown.

Cases are shown by date of notification in contrast to the epidemic curve where the date of onset (symptoms) is shown. Counties A-F refer to Swedish counties. One of the suspected cases from county A was diagnosed abroad, the exact date is unknown and therefore not listed in the timeline.

from 30 May to 10 July 2018 (Figure 2). The age of the cases ranged from $9-92$ years (median 41.5 years) and the majority of the cases were women $(n=13 / 20)$. All cases had domestically acquired HAV infections and came from six different counties in Southern Sweden (Figure 1). The epidemiological investigation was coordinated by PHAS and included a standard questionnaire for hepatitis $A$ on exposures and telephone interviews, conducted by the local Regional Offices of Communicable Disease Control and Prevention. Results showed that all cases had consumed strawberries within 30 days before disease onset and at least 10 cases had consumed strawberry smoothies at two different juice bars of the same franchiser (county A). Five cases had consumed a dessert with sauce made from frozen strawberries at three different elderly homes (county A, B and E) and two cases (from county C and D) reported eating a mix of berries at a breakfast buffet at the same hotel in county $A$. One case had a strawberry smoothie at a restaurant (county $A$ ). The two cases from county $F$ consumed strawberry smoothies served at a school. Environmental investigations and interviews with kitchen personnel revealed that in none of the cases had the strawberries been heated adequately before serving. Strawberries were the only food item that all the cases had in common.
As at 04 October 2018, a total of 36 cases of laboratory-confirmed acute hepatitis A were reported to public health authorities in Austria (since June) of which 14 fulfilled the definition of a confirmed outbreak case and four were classified as non-outbreak cases based on sequence-typing data; for the remaining 18 cases, sequence-typing data are not available and questioning regarding food exposure during their incubation period is ongoing. For the 14 confirmed outbreak cases, disease onset ranged from 8 June to 20 September (Figure 2), the median age was 21.0 years (range $5-70$ years) including eight males and six females. Thirteen were residents in three neighbouring provinces in Eastern Austria. Telephone interviews using a standardised questionnaire on food exposure and purchasing behaviour were conducted with the 14 confirmed outbreak cases and 12 revealed consumption of strawberry ice cream during the incubation period. Out of these, nine remembered the restaurants where they ate the ice cream.

\section{Microbiological findings}

In Sweden, 17 cases were confirmed by sequencing of an overlapping region (692 nt) of the HAV genome (VP1/2A; M14707 position 2683-3374), covering the $460 \mathrm{nt}$ fragment recommended for typing by the global HAV network HAVNET [5]. Six cases, from counties B-F, 


\section{FIGURE 2}

Hepatitis A virus genotype IB outbreak cases by date of onset and country of residence, Austria and Sweden, JuneSeptember $2018(\mathrm{n}=31)$

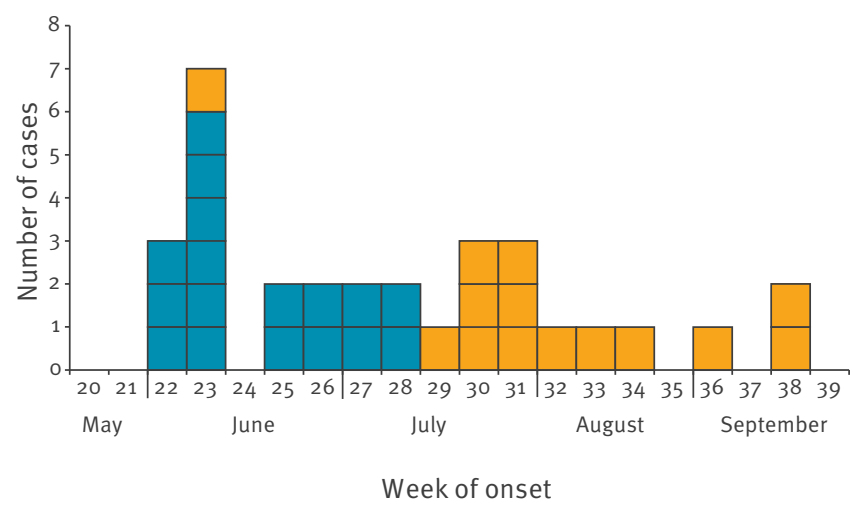

$\square$ Confirmed HAV outbreak cases Sweden $(n=17)$ $\square$ Confirmed HAV outbreak cases Austria $(n=14)$

HAV: hepatitis A virus.

had not visited the juice bars in county A or other franchisers connected to it (Figure 1); sequencing of those cases quickly linked them to the outbreak in county $A$ and interviews later confirmed the cases had all consumed strawberries.

In Austria, the 14 confirmed outbreak cases were identified by sequencing the 460 nt fragment as recommended by HAVNET. Phylogeny revealed that all cases were genetically $100 \%$ identical (Figure 3 ).

Basic Local Alignment Search Tool (BLAST) [6] and HAVNET were used to find an indication of the geographical origin of the outbreak strain $\left(\mathrm{MH}_{730560)}\right.$. No similar or related sequences were identified in neither of the databases. The most closely related sequences were involved in an outbreak of HAV in travellers returning from Egypt in $2013[7,8]$ and from the HAV outbreak affecting the Nordic countries in October 2012-June 2013, which was likely caused by frozen strawberries (Figure 3) [1]. However, the low sequence similarity (98\%) suggests that there is no relation between these outbreaks.

\section{Food investigation and outbreak control}

In Sweden, the Environmental Health Offices in counties $A$ and $B$ traced back the origins of the frozen strawberries used at the juice bars, the elderly homes, schools and at the hotel breakfast buffet (nine locations in total) (Figure 4). Food wholesaler X was identified as a common supplier of frozen strawberries to all locations. From wholesaler $\mathrm{X}$, the strawberries were traced back through a trader in Sweden who had purchased frozen strawberries from producer $\mathrm{Y}$, residing in Poland. Left over strawberries from the wholesaler
$X$ were found in the freezer in one of the elderly homes and were sent in to the NFA. On 26 June, wholesaler $X$ initiated the withdrawal of the incriminated batch of frozen strawberries from the market. The batch was labelled with the best-before date 06 April 2020 (Environment and Health Administration of Stockholm Municipality, Stockholm, personal communication). In total, 1,664 packages with $5 \mathrm{~kg}$ strawberries each (corresponding to $8,320 \mathrm{~kg}$ ) were withdrawn from the Swedish market.

NFA did a laboratory investigation and confirmed the presence of HAV in the left over strawberries on 28 June 2018 by reverse transcription (RT) real-time polymerase chain reaction (PCR). Viral RNA was isolated and sequence analysis demonstrated the presence of the outbreak strain IB in the strawberries with $100 \%$ identity (Figure 3). The identification of the outbreak strain IB confirms the imported frozen strawberries as the common source of this outbreak.

As a consequence of the outbreak, the juice bar chain decided to stop using frozen strawberries in their smoothies and changed to pasteurised frozen pellets of strawberries instead. Staff of the juice bar chain, the elderly home and other persons who had contact with cases were tested for HAV. Other public health measures included preventive vaccination and administration of gamma globulins.

In Austria, AGES performed an extended trace back analysis focusing on the supply of the frozen strawberries used for the production of the outbreak-related strawberry ice cream. The same producer in Poland that had been identified by the Swedish authorities was identified as source of the particular frozen strawberries (Figure 4). Since mid-May 2018, only one wholesaler in Austria has purchased frozen strawberries from the producer $Y$ in Poland-these strawberries had been further distributed to at least 13 wholesalers, two hospital food service kitchens (in Austria), two wholesalers (in Slovakia) and to one ice cream producer (in Italy). In total, about 90 restaurants and cafeterias in Austria were identified as recipients of frozen strawberries originating from producer $Y$ in Poland (Figure 4).

Six of these restaurants and cafeterias could be linked to eight Austrian outbreak cases, through the consumption of strawberry ice cream during the incubation period. Food samples collected from stored packages of frozen strawberries originating from producer $Y$ in Poland (best-before dates 06.03.2020 and 26.06.2020), tested negative for HAV.

The single Austrian importer of frozen strawberries from producer $\mathrm{Y}$, who is expecting a frozen strawberry supply of 22 tonnes at the end of 2018 , has requested evidence for a HAV-negative test result of samples from the next incoming strawberry supply. Furthermore, the Austrian importer has requested a guarantee from the 


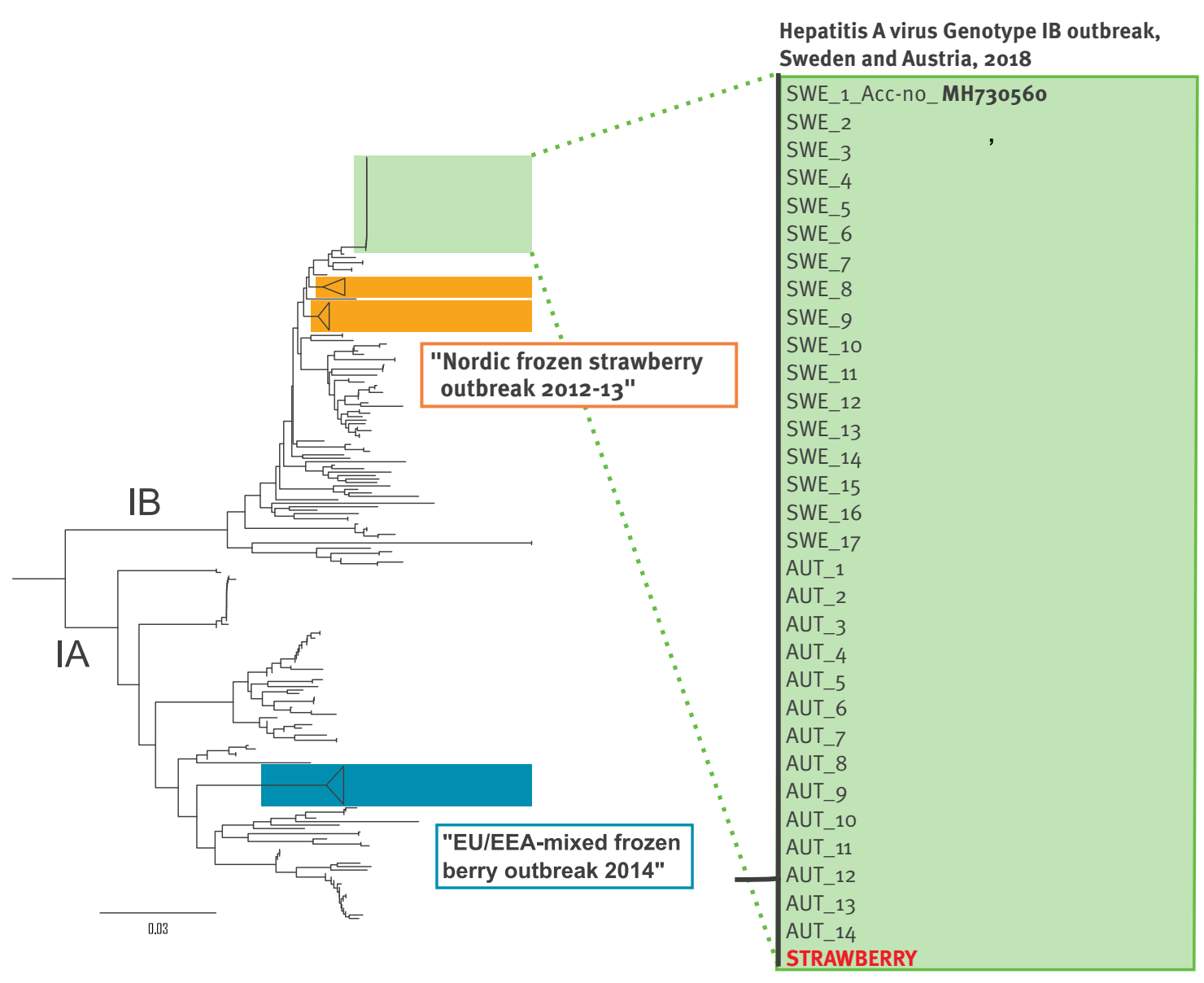

Swedish cases of the berry-related outbreak in the Nordic countries, 2012-13 are highlighted in orange, cases of the multistate outbreak in Europe, 2014 in blue and hepatitis A virus genotype IB outbreak, Sweden, Austria, 2018 are highlighted in green.

The phylogenetic tree was constructed using VP1/2A sequences, Sweden 2013-2018 with the Neighbour-joining method in MEGA7 [22], using the Tamura Nei as evolutionary model, and a bootstrapping approach for the statistical analysis (1,000 replicates). The scale bar indicates the number of nucleotide substitutions per site.

purchasers that frozen strawberries are heated before consumption.

\section{International enquiry}

On 21 June 2018, the PHAS launched an urgent enquiry in the European Centre for Disease Prevention and Control (ECDC) Epidemic Intelligence Information System for Food- and Waterborne Diseases and Zoonoses (EPIS-FWD). At that time, nine countries reported that they had not observed any HAV infections associated with the outbreak sequence (name in EPIS-FWD: 'SW 18-09763'). The sequence was also uploaded and shared on HAVNET. On 27 June 2018, Stockholm municipal authority sent a notification to the national contact point for the European Commission's Rapid Alert System for Food and Feed (RASFF) (Reference number 2018.1813).
On 25 July 2018, Austria reported the first case infected with the same genotype IB outbreak strain in EPIS-FWD (Figure 1).

\section{Discussion}

In Sweden, the incidence rate for hepatitis A infections is low with an average of 0.9 cases per 100,000 population per year from 2010 to 2017 (data not shown). In 2017, it increased slightly due to the ongoing outbreak of hepatitis A disproportionally affecting men having sex with men (MSM) [9-12]. A similar incidence rate holds for Austria with an average of 0.8 cases per 100,000 population per year over the same period; in both countries, hepatitis A is a notifiable disease. In Sweden, cases fulfilling the European Union (EU) case definition for hepatitis A (IgM or HAV RNA positive, with clinical criteria of an acute hepatitis) [13] are reported to PHAS by clinicians or laboratories via an electronic system called SmiNet. Samples are send to PHAS for 
Schematic visualisation of the supply chain of frozen strawberries originating from Poland, hepatitis A virus genotype IB outbreak, Austria and Sweden, June-September 2018

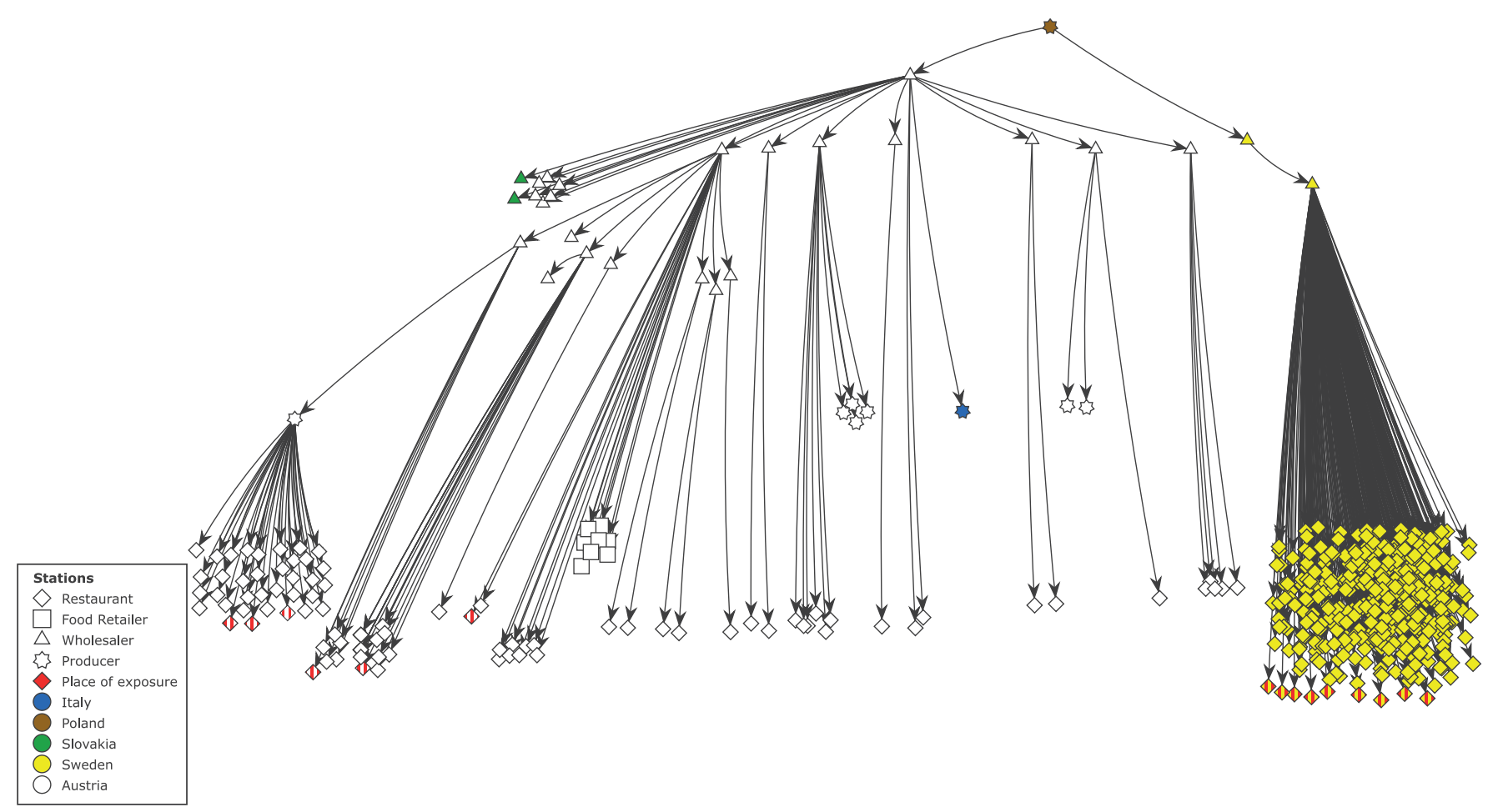

Created with FoodChain-Lab, which is a KNIME extension providing trace back and forward analysis of suspicious food items along food supply chains in case of a foodborne disease outbreak; the open-source software was developed by the German Federal Institute for Risk Assessment (BfR) [23].

Red/white striped diamonds indicate the likely place of exposure $(n=6)$ of eight out of the 14 Austrian confirmed cases and the red/yellow striped diamonds the place of exposure $(n=9)$ of all of the 17 Swedish confirmed outbreak cases linked to the producer in Poland.

typing on a voluntary basis $(60-70 \%$ of the notified cases). In Austria, a case fulfilling the EU case definition is reported by the clinician or diagnosing laboratory to the relevant public health authorities via a web-based, case-recording system called "Elektrisches Meldesystem" (EMS). Within the described hepatitis A outbreak since beginning of August, AGES has implemented an intensified monitoring of cases of hepatitis $A$ registered in the EMS. This includes the prompting to transfer HAV-IgM positive serum samples of reported hepatitis $A$ cases from the primary laboratories to the national reference laboratory (Center for Virology, Medical University of Vienna) for genotyping.

Hepatitis A virus is transmitted through faecal-oral route, via direct person-to-person contact or contaminated food and water [14]. In the current multi-country HAV outbreak with a total of 31 confirmed cases so far, imported frozen strawberries were identified as the vehicle of the outbreak agent. Several large multi-country outbreaks have been reported in the last 5 years related to contaminated berries [1-4], demonstrating that berries are a common source of contamination with HAV and suggesting that they should always be considered in HAV outbreak investigations. On 26 July 2018, almost 2 months after the initial outbreak alert in Sweden, Austria reported a case of HAV infection with a strain indistinguishable from the Swedish outbreak strain, genotype IB. As at 4 October, a total of 14 cases fulfilled the definition of a confirmed outbreak case in Austria. Due to rapid sharing of the outbreak sequence and information on food exposure in the EPIS-FWD enquiry from Sweden, strawberry ice cream was identified as the common link among the Austrian outbreak cases. Trace back investigations in Austria revealed that the respective frozen strawberries were from the same producer $\mathrm{Y}$ in Poland as the frozen strawberries identified as vehicle for the Swedish HAV outbreak.

There are several challenges with HAV outbreaks related to berries: first, the trace back can be difficult as berries are typically harvested by one producer, then packed by another food business operator whereby batches may then be mixed or split. In this outbreak, the country of origin of the strawberries was identified to be Poland and the wholesaler in Sweden who bought the strawberries acted quickly and withdrew the incriminated batch. Since they were only 
distributed to canteen kitchens or large-scale catering establishments (not to retail stores), a list of recipients was available allowing for fast withdrawal of the strawberries from the market. Nevertheless, frozen berries can be stored for a long time in the freezer or end up in multiple different dishes (desserts, smoothies, cakes, etc.), which can complicate tracing. In Sweden, the fast withdrawal together with timely public health measures such as preventive vaccination and administration of gamma globulins to contact persons at affected facilities and heating of frozen strawberries contained the outbreak. As a result, case numbers were relatively small compared with previous reported HAV outbreaks related to frozen berries (e.g. 1,803 cases in Italy, 2013/14) [4].

Although frozen strawberries were also highly suspected during the large HAV outbreak affecting the Nordic countries $2012 / 13$, it was not possible to detect HAV in any of the strawberry samples [1]. In the current outbreak, leftovers from the suspected frozen strawberries in Sweden were sent to NFA and the presence of HAV could be confirmed by real-time PCR and Sanger sequencing, providing evidence for the source of infection. While being invaluable in tracing the source of infections, the molecular detection of viruses in food is challenging $[15,16]$. Reverse transcription (RT) real-time $P C R$ is the standard method for monitoring viral contamination in food [17], but strawberries often contain inhibitors which cause an inefficient amplification of the RNA target sequence [18]. Moreover, the viral load in berries is often low and the viral particles have to be concentrated before performing RT real-time PCR. Many concentration methods are inefficient and may cause co-purification of RT and/or PCR inhibitors present in the food sample [19]. These factors in combination can lead to an underestimation of the viral load as described for other enteric viruses [20]; false negative results are therefore common.

Another point to consider during HAV outbreak investigations is the long incubation period of hepatitis A (up to 6 weeks). After such a long time, it can be difficult to recall food consumption and collect food leftovers. Furthermore, the time from the onset of symptoms to a primary diagnosis and the sequence information can take several weeks.

This HAV outbreak linked to imported frozen strawberries gives reason to re-evaluate the national recommendations for the handling of frozen berries in Sweden. HAV remains infectious during frozen storage and washing with water before consumption has limited effects in removing HAV from berries and herbs [21]. During the large HAV outbreak due to frozen berries in the Nordic countries in 2012/13, the NFA in Sweden recommended to heat frozen strawberries before consumption to inactivate enteric viruses. After the outbreak, this recommendation was dismissed for strawberries. However, the NFA recommends consumers and food business operators to boil frozen, imported raspberries due to the risk of norovirus. The current outbreak demonstrates that boiling recommendations could be considered for frozen strawberries, or all frozen berries as in Denmark, Finland and Norway [1]. This recommendation has been also given in the current hepatitis A outbreak by the Austrian public health authorities.

\section{Conclusion}

In conclusion, the combined epidemiological and microbiological investigations and food trace back analyses identified frozen strawberries as the vehicle of the two-country HAV outbreak. In Sweden, the findings led the wholesaler to voluntarily withdraw this product from the Swedish market. While there were no further reported cases in Sweden since 27 July 2018, the latest outbreak case in Austria occurred in calendar week 34. Based on findings of the trace back analyses identifying supply of the particular frozen strawberries to Slovakia and Italy, occurrence of further cases in other European countries is possible. Increasing awareness will help to accelerate a fast public health response.

This report highlights the importance of fast collaborations between different agencies, and the crucial role of sharing sequencing data of HAV samples between European countries. Without the sequence information, it would have been difficult to allocate single cases in county B-F and cases in Austria to the same outbreak.

\section{Acknowledgements}

We would like to acknowledge all the staff at local and national levels for their contribution in this outbreak investigation.

\section{Conflict of interest}

None declared.

\section{Authors' contributions}

All authors contributed to the local or national outbreak investigations described here. LS posted the initial messages in EPIS. JLE, TE, RE and SP identified the outbreak strain MH730560 (Genbank)/SW 18-09763 (EPIS) and confirmed its presence in the imported strawberries. DS, SWA, LR and SM coordinated the outbreak investigation in Austria, LS and $E L$ in Sweden. CJ and ML did the trace back investigation in Sweden. TE has drafted and written the manuscript. All authors critically revised the work and approved the final version.

References

1. Nordic Outbreak Investigation Team C. Joint analysis by the Nordic countries of a hepatitis A outbreak, October 2012 to June 2013: frozen strawberries suspected. Euro Surveill. 2013;18(27):20520. https://doi.org/10.2807/1560-7917. ES2013.18.27.20520 PMID: 23870076

2. Severi E, Verhoef L, Thornton L, Guzman-Herrador BR, Faber M, Sundqvist $L$, et al. Large and prolonged food-borne multistate hepatitis A outbreak in Europe associated with consumption of 
frozen berries, 2013 to 2014. Euro Surveill. 2015;20(29):21192. https://doi.org/10.2807/1560-7917.ES2015.20.29.21192 PMID: 26227370

3. Fitzgerald M, Thornton L, O'Gorman J, O'Connor L, Garvey P, Boland $M$, et al. ;Outbreak of hepatitis $A$ infection associated with the consumption of frozen berries, Ireland, 2013--linked to an international outbreak. Euro Surveill. 2014;19(43):20942. https://doi.org/10.2807/1560-7917.ES2014.19.43.20942 PMID: 25375902

4. Scavia G, Alfonsi V, Taffon S, Escher M, Bruni R, Medici D, et al. A large prolonged outbreak of hepatitis A associated with consumption of frozen berries, Italy, 2013-14. J Med Microbiol. 2017;66(3):342-9. https://doi.org/10.1099/jmm.0.000433 PMID: 28086079

5. Kroneman A, de Sousa R, Verhoef L, Koopmans MPG Vennema HOn Behalf Of The HAVNet Network. Usability of the international HAVNet hepatitis A virus database for geographical annotation, backtracing and outbreak detection. Euro Surveill. 2018;23(37). https://doi.org/10.2807/1560-7917. ES.2018.23.37.1700802 PMID: 30229723

6. Altschul SF, Gish W, Miller W, Myers EW, Lipman DJ. Basic local alignment search tool. J Mol Biol. 1990;215(3):403-10. https:// doi.org/10.1016/So022-2836(05)80360-2 PMID: 2231712

7. MacDonald E, Steens A, Stene-Johansen K, Gillesberg Lassen S, Midgley S, Lawrence J, et al. Increase in hepatitis A in tourists from Denmark, England, Germany, the Netherlands, Norway and Sweden returning from Egypt, November 2012 to March 2013. Euro Surveill. 2013;18(17):20468. PMID: 23647624

8. Sane J, MacDonald E, Vold L, Gossner C, Severi E, Outbreak Investigation T. Multistate foodborne hepatitis A outbreak among European tourists returning from Egypt--need for reinforced vaccination recommendations, November 2012 to April 2013. Euro Surveill. 2015;20(4):21018. https://doi. org/10.2807/1560-7917.ES2015.20.4.21018 PMID: 25655054

9. Werber D, Michaelis K, Hausner M, Sissolak D, Wenzel J, Bitzegeio J, et al. Ongoing outbreaks of hepatitis A among men who have sex with men (MSM), Berlin, November 2016 to January 2017 - linked to other German cities and European countries. Euro Surveill. 2017;22(5). https://doi. org/10.2807/1560-7917.ES.2017.22.5.30457 PMID: 28183391

10. Beebeejaun K, Degala S, Balogun K, Simms I, Woodhall SC, Heinsbroek E, et al. Outbreak of hepatitis A associated with men who have sex with men (MSM), England, July 2016 to January 2017. Euro Surveill. 2017;22(5). https://doi. org/10.2807/1560-7917.ES.2017.22.5.30454 PMID: 28183392

11. Freidl GS, Sonder GJ, Bovée LP, Friesema IH, van Rijckevorsel GG, Ruijs WL, et al. Hepatitis A outbreak among men who have sex with men (MSM) predominantly linked with the EuroPride, the Netherlands, July 2016 to February 2017. Euro Surveill. 2017;22(8):30468. https://doi.org/10.2807/1560-7917. ES.2017.22.8.30468 PMID: 28251892

12. Ndumbi P, Freidl GS, Williams CJ, Mårdh O, Varela C, Avellón A, et al. Hepatitis A outbreak disproportionately affecting men who have sex with men (MSM) in the European Union and European Economic Area, June 2016 to May 2017. Euro Surveill. 2018;23(33). https://doi.org/10.2807/1560-7917. ES.2018.23.33.1700641 PMID: 30131095

13. European Commission. Commission Regulation (EC) No $2018 / 945$ of 22 June 2018 on the communicable diseases and related special health issues to be covered by epidemiological surveillance as well as relevant case definitions under Decision No $1082 / 2013 /$ EU of the European Parliament and of the Council of 22 October 2013. Official Journal of the European Union. Luxembourg: Publications Office of the European Union. 06/072018: L 170. Available from: https://eur-lex.europa.eu/ legal-content/EN/TXT/PDF/?uri=CELEX:32018D0945\&from=EN \#page $=22$

14. Jacobsen KH, Wiersma ST. Hepatitis A virus seroprevalence by age and world region, 1990 and 2005 . Vaccine. 2010;28(41):6653-7. https://doi.org/10.1016/j. vaccine.2010.08.037 PMID: 20723630

15. Petrignani M, Verhoef L, Vennema $H$, van Hunen $R$, Baas $D$, van Steenbergen JE, et al. Underdiagnosis of foodborne hepatitis A, The Netherlands, 2008-2010(1.). Emerg Infect Dis. 2014;20(4):596-602. https://doi.org/10.3201/eid2004.130753 PMID: 24655539

16. United States. (U.S) Food \& Drug Administration (FDA). Bacteriological analytical manual (BAM) 26B: Detection of hepatitis A in foods. Silver Spring: FDA; Jan 2014. Available from: http://www.fda.gov/Food/FoodScienceResearch/ LaboratoryMethods/ucm374006.htm

17. ISO. (2017). ISO 15216-1 Microbiology of the food chain Horizontal method for determination of Hepatitis A virus and norovirus using real-time PCR, part 1: Method for quantification. ISO (Ed), (First edition 2017-03 ed) Switzerland.
18. Schrader C, Schielke A, Ellerbroek L, Johne R. PCR inhibitors - occurrence, properties and removal. J Appl Microbiol. 2012;113(5):1014-26. https://doi.org/10.1111/j.13652672.2012.05384.x PMID: 22747964

19. Bartsch C, Szabo K, Dinh-Thanh M, Schrader C, Trojnar E, Johne R. Comparison and optimization of detection methods for noroviruses in frozen strawberries containing different amounts of RT-PCR inhibitors. Food Microbiol. 2016;60:124-30. https://doi.org/10.1016/j.fm.2016.07.005 PMID: 27554153

20. Mäde D, Trübner K, Neubert E, Höhne M, Johne R. Detection and Typing of Norovirus from Frozen Strawberries Involved in a Large-Scale Gastroenteritis Outbreak in Germany. Food Environ Virol. 2013;5(3):162-8. https://doi.org/10.1007/s12560-0139118-o PMID: 23888384

21. Butot S, Putallaz T, Sánchez G. Effects of sanitation, freezing and frozen storage on enteric viruses in berries and herbs. Int Food Microbiol. 2008;126(1-2):30-5. https://doi.org/10.1016/j. ijfoodmicro.2008.04.033 PMID: 18547667

22. Kumar S, Stecher G, Tamura K. MEGA7: Molecular Evolutionary Genetics Analysis Version 7.0 for Bigger Datasets. Mol Biol Evol. 2016;33(7):1870-4. https://doi.org/10.1093/molbev/ msw054 PMID: 27004904

23. Weiser AA, Thöns C, Filter M, Falenski A, Appel B, Käsbohrer A. FoodChain-Lab: A Trace-Back and Trace-Forward Tool Developed and Applied during Food-Borne Disease Outbreak Investigations in Germany and Europe. PLoS One. 2016;11(3):e0151977. https://doi.org/10.1371/journal. pone.0151977 PMID: 26985673

\section{License and copyright}

This is an open-access article distributed under the terms of the Creative Commons Attribution (CC BY 4.0) Licence. You may share and adapt the material, but must give appropriate credit to the source, provide a link to the licence, and indicate if changes were made.

This article is copyright of the authors or their affiliated institutions, 2018. 